\title{
Participatory Systemic Inquiry
}

\section{Danny Burns*}

\begin{abstract}
This article explores Participatory Systemic Inquiry processes through two examples of practise. The first is about embedding public engagement in UK higher education, the second is about water infrastructure development and local capacity development in small towns situated around Lake Victoria. These examples illustrate why it is necessary to understand the wider systemic dynamics within which issues are situated, and how this helps to identify workable and sustainable solutions to problems. It describes the learning architectures which were constructed to hold the local and thematic inquiries and then to extend them. It also demonstrates the methods which operationalised these processes and explores some of the methodological differences between this approach and other approaches to qualitative and participatory research.
\end{abstract}

\section{Introduction}

Participatory Systemic Inquiry is an approach to learning and deliberation which involves multiple stakeholders in generating deep insights into the dynamics of the systems that they are trying to change. By a system I mean a web of relations within which any of the issues that people might be concerned with are embedded. This includes amongst others, causal relationships, systems of meaning, norms, power relationships, and social networks. When we map systems we are not trying to map reality, but to build a picture of the different realities experienced by different stakeholders. This will lead to both convergence and divergence amongst stakeholders about what is going on and why. From this understanding situated theories of change can be generated, and opportunities for action can be identified. Participatory Systemic Inquiry can be embedded into longer term Action Research (Reason and Bradbury 2001) or Systemic Action Research (Burns 2007) or can stand alone as a sensemaking process which can inform strategies for action. In this article I want to use two quite different examples. The first is a project that I facilitated between 2009 and 2010 on embedding public engagement in higher education in the $\mathrm{UK}$, and the second is a piece of work that I supported - the Lake Victoria Water and Sanitation Programme in East Africa. The first is an organisational change process. The second operated at the interface between community and institutions. At the end of each case I draw out some of the key characteristics of the process.

\section{Embedding public engagement in higher education}

2.1 Background to the initiative

In 2009 the National Centre for Public Engagement in Higher Education (NCCPE) initiated a national action research programme to explore how to most effectively embed public engagement in higher education. ${ }^{1}$ The rationale for this initiative was a concern that universities were becoming too divorced from people and needed to build new relationships. The NCCPE was part of a wider initiative that had been funded by the Research Councils UK and the Wellcome Trust. The bulk of their investment went into six national beacons in Edinburgh, Wales, Manchester, East Anglia, UCL/Birkbeck, North East England. These were supposed to model different approaches to the organisational change. In the early days of the initiative there was a preoccupation with defining public engagement. It quickly became clear that it meant many things to many people, and also that for some institutions better public engagement meant public lectures and to others it meant a plethora of action research and other co-generation projects. This was problematic because the definitional questions threatened to obscure the inquiry. We decided as a result not to attempt a consensus definition.

Public engagement is not a new idea. The university settlement movement (Bradley 2007) which grew in the early years of the past century (although highly paternalistic) was essentially a series of university-led community development 
programmes which explicitly recognised the universities' responsibility to the communities within which they were located. In the 1960 s the creation of the Open University represented a major challenge to the elite notion of a university, enabling huge numbers of the public to engage with university education for the first time. Others have started to tread this road more recently. The University of Bristol, for example, appointed a Professor of Public Engagement to act as a champion for public engagement and set up a corporate centre of public engagement to provide support to academics. The University of Brighton built its whole strategy around the Community University Partnership Programmes (CUPP) centre ${ }^{2}$ which was rooted in partnerships with communities. Within universities there were many examples of public engagement. University teaching hospitals are deeply engaged with publics, as are organisations like the Institute of Development Studies (IDS) whose core business involves engagement with multiple publics. Science fairs had begun to proliferate, university volunteer programmes were developed and expanded, law clinics providing free advice to members of the public started up, subsidised support to non-governmental organisations (NGOs) and community organisations became more widespread, university facilities were made available to the public and so on. Nevertheless, in most universities public engagement remained relatively marginal. That which did exist was hugely diverse. So in an endeavour to make universities more publicly engaged there was huge potential for learning for change.

The national action research programme on public engagement in higher education was an attempt to create such a learning programme. A number of assumptions underpinned the programme.

1 If multiple institutions were involved in the learning, participants would become seeds within their own institutions and would help to change the dialogue around the issue.

2 By engaging in separate parallel inquiries with different constituencies it would be possible to generate an understanding of the different imperatives faced by different people and then bring them together in dialogue.

3 An organisational learning approach would be far more likely to embed public engagement than some variant of an advocacy campaign although it could be argued that the action research and the NCCPE advocacy work was an effective combination.

\subsection{Programme design}

The focus of this work was on the internal organisational change process, not on public engagement itself. In other words, the core questions weren't about public engagement but rather how public engagement could be facilitated by universities, and on what was preventing and enabling it within the university system. This led us to primarily engage participants from within universities and not the wider publics with whom they might engage.

We convened a series of parallel learning streams. The first group was comprised of academics who had done extensive public engagement work mostly over some decades. They were drawn from the arts, sciences and social sciences. We hoped that their experience, combined with their location within and therefore understanding of the university system, would provide rich insights. The second group was made up of senior managers mostly at deputy and pro-vice chancellor level. These were senior decision-makers who could have a significant impact on both their institutions and on the sector as a whole. The third group was comprised of heads of department. The range of disciplines they represented was wide (media, geography, psychology, environment, history, clinical and health sciences, education, social policy, arts and culture). This group was important because they had to manage the strong internal drivers which pushed activity at department level into research or teaching. The fourth group was made up of the Directors of the Public Engagement Beacon. For this group the action research represented an opportunity to share learning across the pilots and then draw it into the wider learning process. The fifth group of Human Resource Managers was selected because so many of the issues raised had human resource implications.

Each group had a different starting question which they refined in their first meeting. For the public engagement group the question was 'What can we learn from our public engagement work about how best to embed public engagement in higher education?' For the senior managers it was 'What are the strategic drivers which affect public engagement and what 
strategic changes need to be made in order to ensure sustainable public engagement?'. For the heads of department the question was 'How can we balance the competing demands on staff time to ensure that public engagement is embedded in the university?'. For the Beacons group the question was 'How can an intensive investment in public engagement projects translate into sustainable public engagement across the universities?', and for the human resources group the question was 'How do work practices, performance management systems, appraisal and recruitment and promotions systems, etc., need to change to support public engagement?'.

The groups met three-six times each, usually for around three-four hours. They varied in size. The public engagement academics group had a core membership of 17. The Beacons group had seven, the heads of department group had ten, the senior managers group had nine and the human resources group had six people. So around 50 people from 40 different Higher Education Institutions (HEIs) were directly involved in the inquiries. Each group discussion was recorded and a record was kept of all the meetings. The only ones where a separate record was not kept was a series of editing meetings where participants edited the text of the final report live.

Alongside the core inquiries we streamed in other learning processes. We ran inquiry sessions within each of the annual conferences of the NCGPE, we organised a cross-stream research event which drew the different groups together, we engaged with a number of meetings which involved larger numbers of people from the Beacons, and there was a national volunteering event which we also took the inquiry into. These larger meetings extended the reach of the research. As well as this, the University of the West of England convened two meetings - one internally with those who worked on public engagement across the university, and one with external organisations who had a relationship with the university to explore with them how they saw the development of public engagement.

\subsection{Challenges to assumptions}

While some more predictable lines of inquiry emerged on issues such as the Research Excellence Framework (how to mitigate the negative impacts of the REF on public engagement, and how to input into debates about the new impact element which showed promise for public engagement), other lines of inquiry were less predictable and challenged the assumptions of both participants and facilitators. The facilitators thought, for example, that the main preoccupation of the heads of department would be that workload management systems would drive people towards research and teaching and that it would be difficult to build in public engagement without an alternative incentive structure. In fact this was not seen to be a major problem. Most managers felt that they were pretty good at making the systems they had do what they needed them to do. The big issue for them was equity at departmental level. They were concerned that some staff would resent those that did public engagement because it put a greater burden of teaching on them and so on. So the whole issue of equity in relationship to public engagement was put onto the agenda. This opened up other avenues of inquiry. For example, in some institutions people benefited financially from their public engagement activities, and this also raised the danger that some people would be seen to have access to additional income while others did not.

\subsection{Some methodological characteristics of the programme}

The inquiry had the following characteristics which differentiated it from both more traditional research and other some forms of action inquiry/research:

- Multiple inquiry streams and events (engaging large numbers)

- Different starting questions for each of the inquiry strands

- Direct seeding from one group to another

- Collective analysis and co-written outputs.

Multiple inquiry streams and events (engaging large numbers)

This process involved parallel inquiry streams punctuated by large events. Systemically designed action research needs to start from multiple places to ensure that the diversity of the whole system is represented (as much as is possible), that there are multiple potential entry points for action, and that there is engagement from people with different interests across the system. This design (like that of an earlier project that I cofacilitated with the British Red Cross (Burns 2007) directly engaged large numbers of people 
in the research. This created an ownership for the outcomes of the process, and made it much easier to implement the policy outcomes as they had already begun to be enacted. Rigour is ensured because sense-making and analysis is carried out by multiple stakeholders across the system. By mapping the issues and relationships and opening these up to the scrutiny of stakeholders, different interpretations of what is going on are opened to challenge. Because the analysis is carried out by those who are directly affected by the issues, it is likely to be more robust. Secondly, because both the data and the meanings generated in one part of the system are tested in other parts of the system, they are effectively triangulated. The process generates testable and contextualised theories of change to inform change and further analysis.

\section{Different starting questions for each of the inquiry strands}

We were not trying to compare groups by asking them the same question and seeing how they differed. We wanted them to focus on the things that were most important to them, and then to see how they connected to the inquiries of the other groups. Having different starting questions allowed a different narrative to develop and different perspectives to emerge on overlapping issues. It is important to note the intentionality of different starting points, which contrasts starkly with traditional research approaches which would only be able to compare the perspectives of the different groups because they had been asked the same question.

\section{Direct seeding from one group to another}

We asked the groups if they were happy that the other groups saw the notes of their meetings. The notes were anonymised so that quotes came from the group rather than the individual. At the beginning of each meeting participants considered the notes from their last meeting and the issues raised by the other groups. For example, the first meeting of senior managers raised the issue of reputational risk. This was seeded into the other groups. Whereas senior managers were worried that public engagement could lead to media disasters, experienced public engagement academics cited examples of how public engagement mitigated major risks for universities. One issue which criss-crossed the groups emerged from the public engagement academics group and the heads of department group. They both observed that almost all of the effort and incentives for public engagement was either focused at the senior management level or at the level of the academics. They felt that the focus should be on leaders of research and teaching groups, and that those leaders would then be in a position to champion public engagement and plan for it. It would also mean that public engagement could be seen as a group activity so that not everyone had to do it, but managers would be responsible for ensuring that their group delivered it. This whole argument was reinforced by a separate strand of inquiry which was emerging around the drivers within universities to centralise research. It was argued by the public engagement academics group that even if budgets were centralised it was necessary to maintain niche research units, because the various publics engage with real issues - a centre for psycho-social studies, an international development centre, an animation research unit, and so on. A pattern was beginning to build across the groups. As it started to chrystalise, this thinking was streamed into the HR group who had been thinking about individual incentives and rewards. They had been exploring the implications of adding a public engagement element to all recruitment and promotions criteria - such that, for example, you could not be promoted to be a professor if you did not engage with publics. They now needed to explore the implications of a group-based model where not everyone was assessed on the same criteria. This thinking was then taken into the wider NCCPE conference settings where it was tested and refined.

\section{Collective analysis and co-written outputs}

After a number of inquiry sessions for each group, a smaller sub-group of 3-5 volunteers were endorsed by their groups to edit their contribution to the final text of the report. They reviewed the already agreed notes of their inquiry and wrote the text that they wanted to include within the bigger report. This was done collectively on a large screen. As they wrote they talked and synthesised the sense-making that had already been done in the groups. This was a form of collective analysis of the findings. This report drew together some consensus about the systemic dynamics and the different drivers of change playing out at different locations within the system. It identified a series of core issues that ran across the inquiries and these became the chapters of the report. It identified the convergences and divergences of the different 
groups around these issues, and it made a series of recommendations based on what all of the participants could agree on. The final report (Burns and Squires 2011) was tested for its resonance in two national conference events and reflections from both of these were integrated. This process of co-construction and collective validation gave the final report considerable authority. The report should not be regarded solely as an output. It was then taken back into the institutions of the participants and used as a tool to support change.

The full report of the national action research programme on embedding public engagement in higher education is downloadable from the NCGPE website. ${ }^{3}$

\section{The Lake Victoria Water and Sanitation Programme}

My second example illustrates how it is possible to build systemic inquiry processes into a fairly traditional programme. In the end heavy cutbacks in resources strengthened the more traditional elements of the programme, but not before an alternative approach had been modelled in some detail. This process formed the foundations for some of the work that we later carried out in Ghana (Harvey, Burns and Oswald, this IDS Bulletin).

\subsection{Background}

The Lake Victoria Water and Sanitation Programme aimed to:

- Support pro-poor water and sanitation investments in the secondary urban centres in the Lake Victoria region.

- Build institutional and human resource capacities at local and regional levels for the sustainability of improved water and sanitation services.

- Facilitate the benefits of upstream water sector reforms to reach the local level in the participating urban centres.

- Reduce the environmental impact of urbanisation in the Lake Victoria basin.

Its focus was on 'the forgotten small towns', which over the years had received little or no support, yet bore the brunt of rural urban migration. In the first phase, ten towns were involved: Homa Bay, Bondo and Kisii in Kenya; Bukoba, Bunda and Muleba in Tanzania; Masaka (Nyendo), Banda and Kyotera in Uganda; and the border
(Uganda/Tanzania) town of Mutukula. In each of the ten towns, UN-HABITAT (United Nations Human Settlements Programme) funded the installation of new water supply and sanitation facilities. A consortium of four agencies came together to provide capacity development services: UNESCO-IHE (Institute for Water Education), the Federation of Canadian Municipalities, the Gender Water Alliance and the Netherlands Development Organization, SNV. It was originally planned that these would support local capacitybuilders in each neighbourhood, but UN-

HABITAT decided to appoint a regional capacitybuilding organisation. A multi-stakeholder forum was set up in each town which was seen as the focal point for dialogue about the capacitybuilding programme. The rationale for this process was that infrastructure development was situated within a social and economic system and that people and organisations within that system needed to be understood and supported if the implementation of new water services was to be effective. One element of the capacity development programme took the form of systemic action research. I worked as a methodology adviser and accompanied the action research.

As I said earlier, this programme combined more traditional training and skill development approaches to capacity development with more systemic approaches. The first phase involved an extensive systemic inquiry process where a team drawn from all of the collaborating organisations worked for a week in each town. The aim was to 'identify key issues with citizens and their groups, expand understanding as to why water and sanitation services are not working well, and explore ways and means in which actors at all levels can engage in coordinated coherent, and even parallel actions towards service improvements' (Burns 2010). From here the idea was to establish issues that needed training support and to identify complex issues which could be unlocked through ongoing systemic learning processes. Town-level enquiries were to take place every four months to assess overall progress. Meetings of local capacity-builders and senior decision-makers from the different towns were planned to ensure cross-town learning.

This architecture included a number of different learning processes ranging from 'training' to 'cross-town learning forums', but I want to focus on the more innovative systemic inquiry processes. 
Firstly I want to discuss how the systemic inquiry process was carried out ${ }^{4}$ - focusing on the practical methods. Then I want to look at some of the issues that it generated - which illustrate how a systemic approach opens up potential solutions in a way that traditional capacity development processes frequently fail to do.

\subsection{A systemic inquiry process}

The Lake Victoria Water and Sanitation Capacity Building Programme used an inquiry-based methodology which was rooted in systemic thinking (Midgley 2003; Burns 2007). A systemic approach starts with the assumption that all issues and problems are held within a field of inter-relationships and that to create sustainable change we need to understand these interrelationships. Of course, even when we bring together multiple stakeholder perceptions of a system, it is never possible to see the whole system but we can usually reveal the most important relationships. These flow as power relationships (visible and invisible), and chrystalise as norms. Actions to unlock problems can be ineffective because these powerful forces lock any intervention into the system dynamics and pull innovations back towards the prevailing social and economic norms. Conversely, small actions which disturb those system dynamics may have disproportionately powerful impacts. The aim of this process is to understand these systems of relationships so that opportunities to impact on those system dynamics can be identified, theories of change generated, and actions taken.

Many capacity development interventions are based on defining problems in terms of deficits, highlighting 'lack of skills, information, and understanding'. This is problematic because they frequently lead to solutions which are not appropriate, implementable or sustainable within the specific context (Oswald and Clarke 2010). Action inquiry-based methods do not rely on assumptions about 'what isn't' but rather try to establish 'what is' as a platform for generating solutions. Capacity responses therefore (a) engage people on real issues that they see, (b) work to foster action on these, (c) challenge assumptions which restrict the possibilities for action, and (d) nurture many lines of response in a way that allows for complex dynamics to appear and inform solutions. The approach is also based on a belief that not only is it right for local people to determine solutions to their own problems, but that unless they understand and own the process, any gains from capacity-building are likely to be very short lived. This is why we use action research and action inquiry processes.

\subsection{What did the process look like?}

In this section I want to navigate the reader through the actual process that we supported and to talk more generally about how this is done. We started by brainstorming the range of known stakeholders that related to water and sanitation. This included people who we thought might have an overview (however partial) - such as the multi-stakeholder forum, and people on the ground who were directly affected by the issues. New stakeholders quickly emerged during our inquiries. For example, a discussion with the local administrators identified the local health centre as a crucial location for inquiry. This in turn identified a neighbourhood where there was a high concentration of illness resulting from poor sanitation. Further inquiries revealed new questions such as why the health centre was unable to do any preventative public health work. We uncovered important new sites for inquiry simply by walking around. We discovered unknown local community-based organisations (CBOs) from street signs, witnessed domestic practices and paradoxical consumer behaviour which needed further inquiry; observed how close toilets were to the washing-up of dishes and preparation of foodstuffs and so on.

The experience of almost all of the towns that we worked in was that we could organise all but a few meetings or group discussions at very short notice. ${ }^{5}$ This had two important advantages:

- Firstly, it limited the pre-prepared responses and the extent to which groups could be controlled by dominant voices; and

- Secondly, it allowed us to respond rapidly to issues that emerged perhaps hours or days before.

To enable the action research to be flexible and follow opportunistic pathways, groups may have to split as they progress with their inquiries, so some thought should be given to transport and translation options which allow for any splitting which may emerge. The construction of inquiry teams is also important. There needs to be at least one native speaker in each group. It is crucial that translators are briefed not to 
summarise or interpret what has been said. They must translate literally what they have heard, so that their inquiry team hear the issues as they are expressed. If it means slowing down the discussion this is fine, and it can be explained to the people that we are inquiring with.

Inquiry can take many forms. In the early part of this programme it comprised of individual and group discussions, interviews and informationgathering. Later in the programme it moved towards collective sense-making and learning from action. Inquiry questioning and inquiry group facilitation is not like interview questioning or focus group facilitation. These are more oriented to getting answers to predetermined questions, whereas the priority for inquiry-based questioning is to get people to tell their stories and guide their storytelling towards issues that relate to core inquiry questions.

As we were inquiring we were alert to the following:

- The factual information that we needed technical, legal, behavioural, financial.

- Issues that were important to the people affected by what we were exploring. What people felt, what issues and analysis 'resonated' with them and what people felt passionate about.

- Issues that needed to be probed to get a greater depth of knowledge and understanding.

- Observations: What we saw in front of us that was significant. For example, it was not insignificant that there was no water in the toilets at the offices of the council of one of the towns that we visited. They had not paid their water bills so had been disconnected. Also, a file in the offices of the microcredit organisation was labelled AIDS/HIV - this caused us to think about what their relationship to those living with AIDS/HIV might be.

- What conflicts or conflicts of interest were there?

- What differences in perception were there in relation to others we had inquired with?

- What underlying assumptions seemed to be guiding the opinions, behaviours and actions of the group, to what extent were they contestable?

- Were there possible opportunities emerging from the conversation which could be explored further?
In a typical research study we would do all of the analysis after the event. Experienced action research facilitators will do a great deal in the moment, so that promising lines of inquiry can be pursued as they emerge. It is important to trust both our judgement and our intuition as we do this. Sometimes we pick up on things subconsciously which are very important. Taking time to pause after the conversation, or taking a moment for reflection during the conversation, can quickly identify statements that are assumptions, data which contradicts other statements, and so on. But it is not possible to see everything at the time so we need to ensure that analysis takes place after each day's inquiry. This may lead us to go back to certain stakeholders and probe further, or indicate the need for a different inquiry. In observing situations it is crucial to think about whom and what is not present as well as what is present.

Detailed notes needed to be taken of each meeting. It is very important to catch issues as far as possible in the words of those that say them. When summarising a narrative it is too easy to inadvertently place a 'researcher' interpretation on it. We also frequently screen out the detail and are left with headline issues without the detail to follow through later. We would expect a considerable quantity of notes at the end of a process. Typically a one-and-a-halfhour discussion might generate more than ten pages of notes.

Because our inquiries involve engagement with stakeholders, our notes will inevitably be written in relationship to these stakeholders. So, the first stage of bringing together what we had learned was to collate our collective knowledge on flipcharts, using stakeholder headings. This enabled us to:

a Get whole team perspectives on the issues emerging from stakeholders. Sometimes team members will have captured different things or have different interpretations. This stage is akin to putting the different pieces of the jigsaw together so that as much of the story as it is possible to tell is told.

b Allow the team to identify issues which have relationships to more than one stakeholder. Teams should take a flipchart sheet for each stakeholder and outline all of the issues that 
emerged from their various inquiries. Once this is done they should look for patterns and relational chains which run between the stakeholders.

The second stage involved the groups mapping all of the issues onto a huge sheet of paper (the size of maybe eight sheets of flipchart paper). Here our aim was not to get a neat version of relationships, but to get as much as possible down and to indicate many different possible relationships. Everyone wrote into the maps, but it was essential to be disciplined about the colours and symbols that we used to ensure that they would also be useful in our cross-town inquiries. We used the following colour coding:

- Blue - People, organisations and locations. For example, boys, girls, UN-HABITAT, schools, homes, shops, borehole, kiosk.

- Green - Points of fact, observations or descriptions of what was happening. For example, there are 50 children at the orphanage; water costs 50,000 shillings to connect; the orphans go to the solid waste bank and sort it, collecting the straws for making crafts and the remainder for making charcoal briquettes.

- Red-Issues, and observations which underpin issues; for example, contractual delays; technological solutions aren't taking women's needs into account; there are few water points because there is little land available; people are choosing to pay more for less clean water. Issues will usually derive from an observation. For example, we may notice that there are only five public water kiosks in the town. Underneath these issues we write quotes, more detailed explanations of the dynamics of an issue, and short stories in ballpoint (not marker pens). This gives the map two levels of resolution.

- Black - Emerging inquiry questions, assumptions that have been challenged, possible action points. For example, could the orphanage be a local capacity-builder? Do we need to find out more about this land issue? Is there evidence that the vendors are sabotaging water points?

Photographs were taken to illustrate the context and the issues; for example pictures of toilets/latrines, washing-up, broken water pumps, queues, how things are located. The maps were also supported by more detailed stories which we attached. These were typically between a page and half-a-page long. They recounted a chain of interlinking issues which resulted in water failure, or told the story of how individual people were affected by water issues. For example, the story of a man who put in his money and lost his business to support a microcredit scheme which didn't work because of contracting issues, and the story of a woman who had to carry heavy jerry cans with a child on her back.

The third stage involved taking segments of the maps and trying to understand the system dynamics. Here we used the same colour scheme, but everything that went onto the map was discussed and decided collectively (including alternative versions of what was going on). The aim of the third stage was to get a distilled picture of the issues and how they related to each other. What we were doing was taking a specific segment of the large map and 'blowing it up' to allow us to zero in, in more detail on the system dynamics that underpinned the issue. The focus on issues is because:

1 Issues relate to many stakeholders across the maps and capacity-building responses may involve many actors in relation to an issue. Locating issues under each stakeholder will lead to substantial repetition and confusion on the maps.

2 The aim of the maps is to understand system dynamics so that we can understand how issues are related to something else that happens in the system. It is only then that we can understand what sort of interventions might be most effective to resolve issues and open up new opportunities.

When we were mapping issues we were essentially looking for two things:

- Relationships (which might be cause-effect relationship, power relationships or other relationships)

- Patterns.

We were also looking for information and insight which might help to explain how and why these existed, and we were seeking to generate better questions to ask of the situation. An example of a simple cause-effect relationship explored in this systemic inquiry process was: 
Figure 1 Nyendo market emerging issues

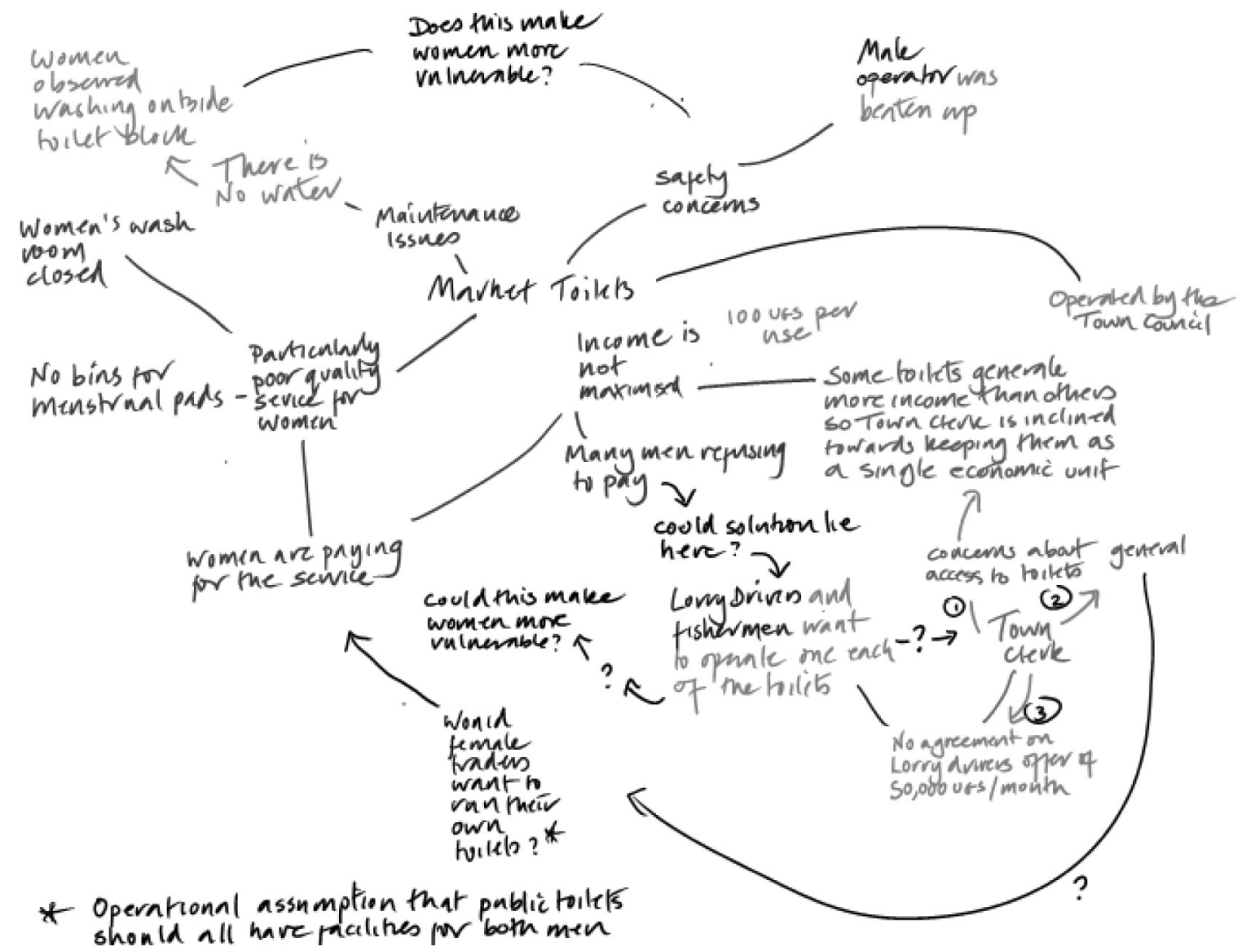

Note The original chart contained colour-coding.

- The introduction of a water point threatens the livelihood of water vendors and leads to vandalism.

A more complex example of multiple interacting cause-effect relationships was captured as follows:

- Poor hygiene conditions result from poor drainage.

- People are building onto the sides of the road affecting the main drains, and there is no effective means of enforcement from the city council.

- It is impossible to build tributary drains because land prices are high as a result of growth in the town and as a consequence people won't give up land for shared facilities.

- Because land prices are high, small plots of land are sold frequently and the land gets more and more fragmented. As a result insanitary conditions get worse because there is no space for new pit latrines. This leads to flying toilets. ${ }^{6}$
- There is no effective solid waste management system to mitigate these problems.

Cause-effect relationships would appear to denote simple linear relationships, but as we can see above, multiple linear relationships can create a highly complex system dynamic which serves to reinforce problems. As each person recounted and mapped the stories that they had heard we also noticed patterns emerging across the inquiries:

- It appeared that girls aged 12-15 are least likely to be attending school.

- There is a strong relationship between poor sanitary conditions and land issues across three towns.

- People are buying dirty water at a higher price than they could pay for clean water.

Having identified the patterns and the issues which underpinned them, we were able map the inter-relationships around them. 
So to summarise: There were three stages to bringing the knowledge(s) back together. First, they were flipcharted under stakeholder headings. Second, the issues were put onto large issue maps which everyone wrote onto. Third, sections of these issue maps were taken onto new maps to explore the detailed relationships.

\subsection{So what did we discover?}

The work uncovered different sorts of issues:

a Complex problems that involved multiple stakeholders. Examples included observations that school toilets weren't being used by girls and that as a result girls weren't going to school during menstruation, or (as above) that poor drainage was a result of complex land issues, or that UN-HABITAT programmes were not reaching the poor, or that people were buying dirty water at 200 shillings per jerrycan when they could get clean water for 100 shillings.

b Opportunities that lay in the relationships between stakeholders and raised questions at the level of the system.

Figure 1 is a simplified issue map (stage three as described above) loosely drawn from issues which emerged in the Nyendo market inquiry.

Many inquiry questions are generated from it.

- Why is it that market lorry drivers and fishermen want to operate their own toilets, and are there others that equally might run the toilets?

- What are the implications for women if these toilets are run by male lorry drivers?

- If the more profitable ones are sold how does that affect the council's ability to provide generic toilets for market users and traders?

- Have they thought about who will maintain the toilets?

- Is there any scope for the fishermen and the lorry drivers to work together?

- Might this provide opportunities for female traders?

- How will they ensure that people pay given that operators have already been victims of violence?

It became apparent that an opportunity for the women might lie in the space opened up by the lorry drivers and the fishermen's separate request to operate one each of the toilet blocks. Might the women traders also want to operate a women-only toilet? This exposed an interesting assumption (which could be examined across the whole programme leading to a more strategic inquiry) that all public toilets were constructed for both genders - men on one side, women on the other. In the case of Nyendo where there are four toilet blocks in separate corners of the site, is there a reason why one shouldn't be for women only?

Another example was the land issue identified in Bugembe. These were some of the issues that were mapped. The council is landless. So it allocates public land for certain public use; as a result there is no space for latrines or garbage dumps; this means that garbage is piling up, pit latrine toilets remain in use despite laws that demand that waterborne sewerage systems should be built in urban settings, and that the proliferation of closely packed pit latrines is contaminating ground water sources. The new town council intends to absorb Wanyanga (upper areas) and moves to do this are in advanced stages. It is likely that this will happen. This will give the council a lot of public land. However, this will all be in one side of town, and may result in all public services being provided in this richer area. There are multiple titles for the same piece of land. The traditional Kyabazinga Kingdom, the church and the Muslim faith all own tracts of land. The council, these institutions, and individuals claim to legally own the same tracts in some cases.

This led to some discussion about the creation of a 'land ownership and management' enquiry group of council, Kyabazinga, Church of Uganda, Catholic Church, Muslims on (public) land availability and management. Other systemic inquiries which were proposed included:

a Slaughter slab waste disposal in the Kyabazinga-owned marketplace;

b Public toilets in key market locations;

c Land improvement for public use, including drainage, rubbish collection points, potential sewer lagoon sites.

More practical training support was identified such as developing business skills to secure a commercially self-standing way of collecting, processing and recycling waste, in conjunction with the Jinja dumpsite. Also the group saw more 
immediate possibilities for brokering a deal between the National Water and Sewerage Company and the public land-owning actors to develop a town waterborne sewer system. The maps enabled a visual clarity about the system dynamics that needed to be subverted and where the opportunities for intervention might lie.

\subsection{Methodological characteristics}

A number of the methodological characteristics of the public engagement in higher education programme described in section 2 are shared by this one. I won't rehearse these but would ask readers to look back at them to see how they map on to this process. There are some further methodological observations that should be noted about this programme in particular which I think are significant.

The programme was underpinned by systemic mapping: visualising the dynamics of a system has proved to be an effective process for collective analysis, and a very powerful way of identifying entry points/opportunities, points of leverage for action. It is also a good way of layering new participants into an ongoing inquiry - as the explanation of what has happened before lies clearly visible in the maps. People across cultures often find it easier to work with visual representations of issues. We do need to take into account language and literacy. In this case the maps were constructed in English, but there are other examples where we have constructed bilingual maps and/or replicated maps in more than one language.

Large inquiry teams: During the first inquiry stage we had a team of 20 or so people to work intensively across four towns for a week. The teams were comprised of SNV staff from Uganda, Tanzania and Kenya, two or three each from the other consortium partners, as well as me and a representative from UN-HABITAT. The country teams all worked in each other's countries to ensure learning travelled between the countries. This might be seen as an unusually large team, but it is by no means unique. For example, I recently observed a piece of youth research in the Karamoja region of Uganda, where a group of around 20 young people built an inquiry team to carry out research into the livelihoods of local pastoralist communities and the issues that they faced following years of conflict and food scarcity. ${ }^{7}$ This illustrates how a momentum can be built quickly around an intense process of research. It is of course not the only way to do it. The same processes can be used with smaller teams.

Mixed research teams combined engineers with social scientists and NGO practitioners. By researching together they began to understand each other better. The technicians were able to see how significant the social system was to the choices of technology that were developed, the possibilities for intervention, and the sustainability of any programmes that were developed. A similar process happened when we brought senior decision-makers into the process. This happened in two ways. Firstly, we intentionally brought into the research team an influential official of UN-HABITAT. Her perspective was transformed by the process. Secondly, we opportunistically engaged a government minister in the analysis of our maps. She happened to be staying locally. She was drawn in instantly, and asked for a report of the process to be sent to her office as soon as it was completed. Engaging senior decision-makers in the research is a much more powerful way to transfer learning than presenting them with a report of the research.

\subsection{Some final reflections on the nature of the systemic process and the role of the action researcher}

In the examples above it is important to understand the role and positionality of the external action researcher/facilitator. In both of these processes the action research was initiated externally by a donor, and was supported by action researchers with a strong commitment to participation. The aim of both processes (as with others in this IDS Bulletin) was to open up inquiry spaces that can be developed and owned by local stakeholders on the ground, but we have to be clear that the design and conception of neither were 'community' driven. This raises some deeper questions about differences in action research approaches.

Participatory Systemic Inquiry processes do not map perfectly onto Participatory Action Research (PAR) processes. At its 'purest', Participatory Action Research is driven entirely by a community or constituency who has identified a set of issues that they need to build knowledge and insight into in order to counteract oppressive power relationships. 
Systemic practitioners/facilitators see power relationships as highly dynamic flows through complex webs of inter-relationships. To even begin to understand them, it is necessary to see them through multiple perspectives. This means engaging and working with people that have completely different interests within the system. Furthermore a key learning from my work has been that to unlock the issues, the inquiry has to follow the issues, which means that different people may need to be involved as the inquiries deepen and the underlying issues become apparent. This contrasts with PAR where the inquiries are rooted with a constituency of people. In this context the facilitators have a great deal more power over decisions about inquiry directions. So while in Participatory Systemic Inquiry (and Systemic Action Research) facilitators will use highly participative processes to bring these perspectives into relation to each other, to collect information, and to collectively

\section{Notes}

* Special thanks to Stuart Worsley of SNV who developed this methodology for the Lake Victoria Water and Sanitation (LVWATSAN) capacity development programme with me and whose voice was ever present in this process, and to Heather Squires (co-facilitator and Programme Manager of the NCCPE Action Research), Paul Manners and Sophie Duncan of the National Coordination Centre for Public Engagement in Higher Education. Thank you to Stephen Wood and Richard Douglass for their organisation and editing work. Specific thanks to Alfredo Ortiz Aragón and Katy Oswald for their detailed comments on this text, and to the other authors of this IDS Bulletin for their important contributions.

1 My role was as Academic Director and Lead Facilitator of this process.

\section{References}

Bradley, K. (2007) 'Creating Local Elites: The University Settlement Movement, National Elites and Citizenship in London, 1884-1940', in S. Couperus, C. Smit and D.J. Wolffram (eds), In Control of the City: Local Elites and the Dynamics of Urban Politics, 1800-1960, Groningen Studies in Cultural Change 28, Walpole MA: Peeters, United States: 81-92

Burns, D. (2010) 'Lake Victoria Water and Sanitation Capacity Building Programme analyse it, they (we) do exercise judgement (and power) in the process of constructing a learning architecture for this. There are major trade-offs here between the imperative to understand power flows through the engagement of multiple actors with very diverse perspectives, and the imperative for a participative process that is driven by those who are most oppressed by those power relationships. Finding ways to manage this tension is a perhaps the biggest challenge for me. The work we did in Ghana (Harvey, Burns and Oswald, this IDS Bulletin) came closest to bridging this gap. That project was initiated and rooted within the community radio station which became a hub for multiple inquiries, but this still asks questions about the positionality of the radio stations themselves. This is not a right and wrong issue. There are trade-offs in the ways in which we engage with power and the ways in which we develop the participatory process which need to be continuously reflected upon.

2 See www.publicengagement.ac.uk/how/casestudies/cupp-helpdesk/.

3 See www.publicengagement.ac.uk/how-wehelp/our-publications/embedding-pe/.

4 What follows is drawn heavily from a methodology paper which I produced for the four organisation consortium after we had piloted the process during the first inception period.

5 Although it should also be noted that considerable attention was given to the right protocols for notifying local leaders of our presence and purpose and gaining their support for our engagement.

6 A flying toilet is where people defecate into a plastic bag and throw it.

7 Scott-Villiers, www.ids.ac.uk/files/dmfile/ StrengthCreativityLivelihoodsofKarimojong Youth.pdf (accessed 21 February 2012).

Systemic Action Research Methodology', unpublished

Burns, D. (2007) Systemic Action Research: A Strategy for Whole System Change, Bristol: Policy Press

Burns, D. and Squires, H. (with participants from the National Action Research Programme) (2011) Embedding Public Engagement in Higher Education: Final Report of the National Action Research Programme, Bristol: National Centre for Public Engagement in Higher Education (NCGPE) 
Midgley, G. (2003) Systems Thinking, London: Sage Publishing

Oswald, K. and Clarke, P. (eds) (2010)

'Reflecting Collectively on Capacities for

Change', IDS Bulletin 41.3, Brighton: IDS
Reason, P. and Bradbury, H. (2001) The Sage

Handbook of Action Research: Participative Inquiry and Practice, London: Sage 